\title{
Androgen metabolism in prostate cancer: from molecular mechanisms to clinical consequences
}

\author{
K-H Chang ${ }^{1,4}$, C E Ercole $e^{2,4}$ and N Sharifi ${ }^{\star 1,2,3}$ \\ ${ }^{1}$ Department of Cancer Biology, Lerner Research Institute, Cleveland Clinic, Cleveland, OH, USA; ${ }^{2}$ Department of Urology, \\ Glickman Urological and Kidney Institute, Cleveland Clinic, Cleveland, OH, USA and ${ }^{3}$ Department of Solid Tumor Oncology, \\ Taussig Cancer Institute, Cleveland Clinic, Cleveland, OH, USA
}

\begin{abstract}
Despite our most vigorous efforts, prostate cancer remains the second leading cause of cancer death in men. Understanding the intricacies of androgen metabolism is vital to finding therapeutic targets, particularly with progression of advanced prostate cancer after initial hormone therapy, where adrenal precursors are involved. Such is the case with castration-resistant prostate cancer, where adrenal androgens, for example, dehydroepiandrosterone, are a source for intratumoural synthesis of dihydrotestosterone. As prostate cancer progresses, androgen metabolism changes due to altered expression of steroidogenic enzymes and mutations in the components of the steroidogenic machinery. These alterations sustain disease and allow progression; mechanistically, they may also enable development of hormone therapy resistance. With the development of the newer agents, abiraterone acetate and enzalutamide, efforts have been made to better define the basis for response and resistance. This work can be carried out in cell lines, animal models, as well as with ex vivo analysis of tissues obtained from patients. Efforts to further elucidate the finer details of the steroidogenic pathway are necessary to move toward a curative paradigm for patients with localised disease at high risk for recurrence.
\end{abstract}

Prostate cancer is the most common non-skin malignancy and the second leading cause of cancer death in men (Siegel et al, 2013). Localised prostate tumours are potentially curable by radiation or surgery. For advanced prostate cancer, androgen deprivation therapy (ADT) by surgical or medical castration is the standard frontline therapy and is initially effective in most patients (Sharifi et al, 2005). However, metastatic disease almost always progresses to castration-resistant prostate cancer (CRPC), which is generally incurable (Attard and de Bono, 2011). Several mechanisms have been proposed to explain this progression of ADT-responsive prostate cancer to CRPC, including, but not limited to, overexpression of the androgen receptor (AR), mutations in the AR, altered recruitment of transcription cofactors, and sustained intratumoural synthesis of dihydrotestosterone (DHT) (Scher and Sawyers, 2005; Labrie, 2011; Sharifi, 2013a). These mechanisms serve as potential therapeutic targets in CRPC treatment, as illustrated by the examples of abiraterone acetate and enzalutamide. Abiraterone acetate blocks adrenal androgen production by inhibiting CYP17A1 activity to suppress tumour growth and so leads to extended survival for patients with CRPC (de Bono et al, 2011; Ryan et al, 2013). Enzalutamide directly inhibits the AR and prolongs survival (Scher et al, 2012). This clinical outcome provides proof for the notion that androgen metabolism and the AR are keys to CRPC progression. However, despite a lengthening of overall patient survival, the tumour cells inevitably develop resistance to abiraterone acetate and enzalutamide, and patients subsequently die from their disease.

In this review, we discuss how androgen metabolism occurs in CRPC and define how recurrent tumour cells utilise precursor steroids to survive in a low-testosterone ( $\mathrm{T}$ ) environment, a circumstance that offers an opportunity to identify new potential drug targets. We briefly review initial studies of the preoperative use of agents targeting androgen metabolism, with results not uncommonly showing complete or near-complete pathologic

\footnotetext{
${ }^{\star}$ Correspondence: Dr N Sharifi; E-mail: sharifn@ccf.org

${ }^{4}$ These authors contributed equally to this work.
} 
response. Finally, we also discuss the usefulness of ex vivo analysis of prostate tissue to better understand the intricacies of androgen metabolism in localised prostate cancer.

\section{ANDROGEN METABOLISM IN CRPC}

Circumventing the need for $\mathrm{T}$ for DHT synthesis. ADT (by suppression of gonadal $\mathrm{T}$ ) is usually initially clinically effective in advanced prostate cancer. However, in addition to the testes, the adrenal glands are a source of androgen production and are likely to provide fuel for tumour growth, even in the presence of ADT. Indeed, a physiologically significant amount of DHT has been detected in recurrent tumours (Geller et al, 1978; Titus et al, 2005; Montgomery et al, 2008), probably indicating that adrenal androgens are an important source for DHT synthesis in ADTtreated tumours. It is now clear that after ADT, sustained concentrations of intratumoural DHT-the most potent AR agonist-can be achieved by conversion from androgen precursors of adrenal origin (Sharifi, 2013b). Adrenal androgens, including dehydroepiandrosterone (DHEA) and its sulfated form, DHEA-S, are abundant in the circulation. To synthesise DHT in the target organ, DHEA is first converted to androstenedione (AD) by oxidising the $3 \beta$-hydroxyl to a 3-keto group and isomerising $\Delta^{5}$ to $\Delta^{4}$ (Figure 1). This rate-limiting step of adrenal androgen metabolism is catalysed by $3 \beta$-hydroxysteroid dehydrogenase/ $\Delta^{5} \rightarrow \Delta^{4}$ isomerase enzymes ( $3 \beta$ HSDs; encoded by HSD $3 B$ ). There are two human $3 \beta \mathrm{HSD}$ isoenzymes, $3 \beta \mathrm{HSD} 1$ and $3 \beta \mathrm{HSD} 2$. The former is predominantly expressed in peripheral tissues including the prostate, whereas the latter is mainly expressed in the adrenal glands, ovaries, and testes (Simard et al, 2005).

The subsequent conversion of $\mathrm{AD}$ to $\mathrm{DHT}$ requires $17 \beta \mathrm{HSD}$ $(17 \beta \mathrm{HSD} 3$ and AKR1C3; encoded by HSD17B3 and AKR1C3, respectively) to reduce the 17 -keto moiety to $17 \beta$-hydroxyl (Adeniji et al, 2013), and steroid- $5 \alpha$-reductase ( $5 \alpha$-reductase- 1 and $5 \alpha$-reductase- 2 ; encoded by $S R D 5 A 1$ and SRD5A2, respectively) to perform the $5 \alpha$-reduction (Figure 1). The canonical pathway of DHT production involves $\mathrm{T}$ as a necessary intermediate, such that steroid reduction by a $17 \beta \mathrm{HSD}$ isoenzyme occurs before $5 \alpha$-reduction. Thus, $\mathrm{AD} \rightarrow \mathrm{T} \rightarrow \mathrm{DHT}$ has traditionally been the generally accepted pathway for DHT synthesis from adrenal androgens in CRPC. However, like T, AD possesses a 3-keto, $\Delta^{4}$ structure, which makes $\mathrm{AD}$ a potential substrate for SRD5A isoenzymes. With this possibility, AD is converted to
$5 \alpha$-androstanedione ( $5 \alpha$-dione), and DHT is synthesised from $5 \alpha$ dione as its immediate precursor. This alternative pathway, which we refer to as the ' $5 \alpha$-dione pathway', circumvents T as a required intermediate (Figure 1). To test which pathway prevails in CRPC tumours, we performed metabolism studies with $\left[{ }^{3} \mathrm{H}\right]$-labelled $\mathrm{AD}$ and quantitatively tracked downstream metabolites using highpressure liquid chromatography (Chang et al, 2011). In six different human CRPC cell line models and two metastatic tumours obtained within minutes of biopsy from patients with CRPC, metabolic flux from $\mathrm{AD}$ to $5 \alpha$-dione uniformly and consistently predominated overflux from $\mathrm{AD}$ to $\mathrm{T}$, demonstrating that in CRPC, tumours use the $5 \alpha$-dione pathway that avoids the need for $\mathrm{T}$.

\section{Altered steroidogenesis in CRPC}

Altered expression of steroidogenic enzymes. In disease that progresses after ADT, because prostate tumour growth still generally depends on androgens, the transcript expression of steroidogenic enzymes is often altered in tumour cells, likely promoting CRPC progression. Transcripts of HSD3B1, HSD3B2, SRD5A1, AKR1C3, and HSD17B3 are increased, probably facilitating DHT synthesis (Titus et al, 2005; Stanbrough et al, 2006; Montgomery et al, 2008). Intriguingly, the SRD5A2 transcript is consistently decreased in CRPC, which seems contradictory to the idea that DHT synthesis is enhanced by steroidogenic enzymes. However, $5 \alpha$-reduction might be compensated for by upregulation of SRD5A1. Furthermore, $\mathrm{AD}$ is a better substrate than $\mathrm{T}$ for SRD5A1 (Thigpen et al, 1993; Russell and Wilson, 1994), which may help to explain why the $5 \alpha$-dione pathway that circumvents $\mathrm{T}$ predominates in CRPC.

Interestingly, in some studies, aromatase, which converts both $\mathrm{AD}$ and $\mathrm{T}$ to oestrogens, is highly overexpressed in CRPC, suggesting a role for oestrogens in resistance (Montgomery et al, 2008). This also introduces the possibility that multiple enzymes (SRD5A1 and aromatase) might compete for common substrates (AD and $\mathrm{T}$ ).

Although there is evidence to suggest that changes in the steroidogenic enzyme transcriptional profile helps cancer cells to proliferate in the low-T environment, it is unclear what drives altered transcriptional regulation of these genes in CRPC. Does aberrant signal transduction leads to an increase in steroidogenic enzyme expression during CRPC progression? How are transcription factors involved in upregulating steroidogenic enzyme gene

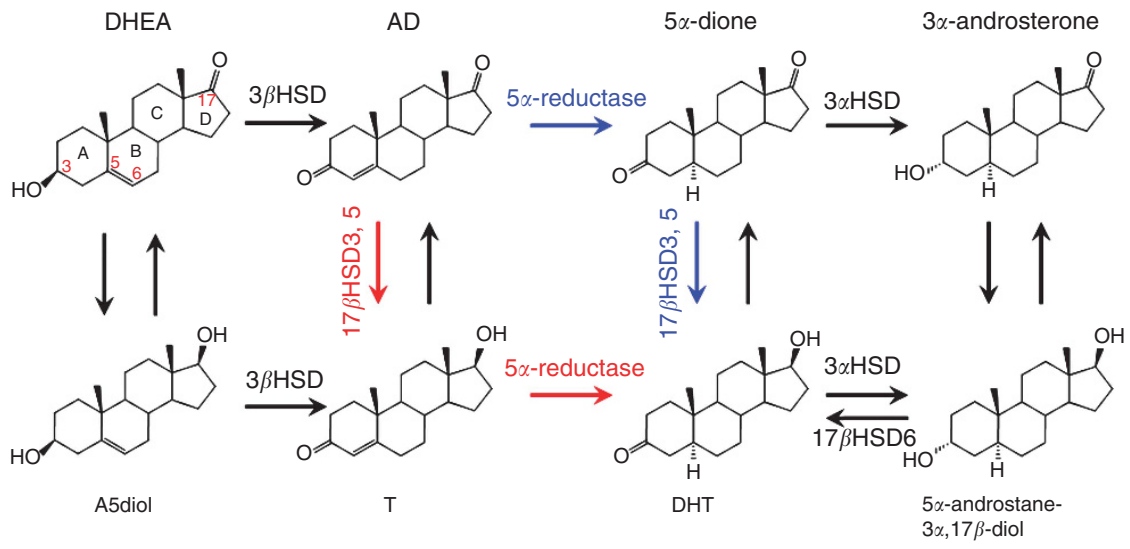

Figure 1. Conversion from DHEA to DHT requires $3 \beta$-hydroxysteroid dehydrogenase (3 $\beta$ HSD), steroid- $5 \alpha$-reductase (SRD5A), and $17 \beta$-hydroxysteroid dehydrogenase (17 $\beta \mathrm{HSD})$ isoenzymes. The initial rate-limiting reaction converts the $3 \beta$-hydroxyl group to a 3 -keto moiety and isomerises the $\Delta^{5}$ to a $\Delta^{4}$ structure, which is catalysed by $3 \beta \mathrm{HSD}$ and produces $\mathrm{AD}$ as an intermediate metabolite. In the conversion of $\mathrm{AD}$ to $\mathrm{DHT}$, metabolic flux can occur either through $\mathrm{AD} \rightarrow \mathrm{T} \rightarrow \mathrm{DHT}$ (the conventional pathway, shown in red) or $\mathrm{AD} \rightarrow 5 \alpha$-dione $\rightarrow \mathrm{DHT}$ (the $5 \alpha$-dione pathway, shown in blue). The $5 \alpha$-dione pathway is the major pathway utilised for DHT synthesis from adrenal precursors in CRPC. Abbreviations: $3 \alpha H S D$, $3 \alpha$-hydroxysteroid dehydrogenase; $A D, \Delta^{4}$-androstenedione; A5diol, $\Delta^{5}$-androstene-3 $\beta, 17 \beta$-diol. 
expression in CRPC? In addition, mechanisms underlying the post-transcriptional regulation of these steroidogenic enzymes are largely obscure. Further investigation is required to elucidate posttranslational modifications that affect steroidogenesis and promote progression to CRPC, possibly with protein phosphorylation, ubiquitination, and acetylation.

Mutations in components of the steroidogenic machinery. Apart from aberrant gene expression, genetic alterations such as PTEN loss and TMPRSS2-ERG translocations have been extensively characterised, and are critical in the development and progression of prostate cancer ( $\mathrm{Li}$ et al, 1997; Tomlins et al, 2007). However, evidence has been lacking for dysregulated steroidogenesis resulting from mutations in enzymes involved in androgen metabolism that enable the development and progression of CRPC. Comparison of adrenal androgen metabolism in the LNCaP and LAPC4 human CRPC cell line models reveals a phenotypic divergence with respect to metabolic flux of DHEA to AD (Chang et al, 2013). Metabolic flux in LNCaP cells is very robust, with $\mathrm{DHEA}$ being quickly converted to $\mathrm{AD}$. $\mathrm{AD}$ is further converted to $5 \alpha$-dione and DHT. In contrast, metabolic flux in LAPC4 is very slow, and synthesis of $\mathrm{AD}$ and other downstream metabolites is quite limited.

HSD3B1 and HSD3B2 encode for the two isoenzymes that are responsible for the conversion of DHEA to $\mathrm{AD}$. We examined the coding sequences of $H S D 3 B 1$ and HSD3B2 in prostate cancer cell lines and found a single missense change that replaces the nucleotide A with $\mathrm{C}$ at position 1245 of HSD3B1. This mutation coincides with a germline single-nucleotide polymorphism that occurs with an approximately $22 \%$ allele frequency in the general population (http://genome.ucsc.edu/). Cell lines demonstrating robust conversion of DHEA to $\mathrm{AD}$, such as $\mathrm{LNCaP}$ and $\mathrm{VCaP}$, have HSD3B1(1245C) (encoding for 367T in $3 \beta \mathrm{HSD} 1$ ). In contrast, LAPC4 and other cell lines exhibiting limited metabolic activity carry HSD3B1(1245A) (encoding for $367 \mathrm{~N}$ ). Furthermore, the more robust metabolism of DHEA to DHT conferred by mutant $3 \beta \mathrm{HSD} 1(367 \mathrm{~T})$ provided a growth advantage in an in vivo xenograft study (Chang et al, 2013). The mechanism underlying rate-limited conversion from DHEA to DHT, probably occurring in the usual setting, is attributable to rapid $3 \beta \mathrm{HSD} 1(367 \mathrm{~N})$ protein turnover, due to its preferential interaction with the ubiquitin E3 ligase, autocrine motility factor receptor, and degradation via the $26 \mathrm{~S}$ proteasome. Importantly, $3 \beta \mathrm{HSD} 1(367 \mathrm{~T})$ would likely also regulate any de novo synthesis from cholesterol that might occur, in addition to metabolic flux from adrenal precursors, as $3 \beta \mathrm{HSD} 1$ is required for all pathways that lead to DHT synthesis.

The clinical significance of these findings is evidenced in part by the observations that, in human CRPC tumours, genetic selection occurs for (a) a somatic mutation in HSD3B1(1245C) in patients with homozygous wild-type inheritance and (b) loss of heterozygosity of the wild-type copy in patients with heterozygous inheritance. A role for this mutation in the development of resistance to newer and more potent hormonal therapies is suggested by the occurrence of the same somatic mutation in a mouse xenograft model treated with abiraterone acetate. Whether mutant $3 \beta \mathrm{HSD} 1$ directly contributes to more robust DHEA metabolism and increases DHT concentrations in patient CRPC tumours remains to be determined by ex vivo metabolism assays with freshly obtained CRPC tumours harbouring mutant 3 $\beta$ HSD1(367T).

The proportion of CRPC tumours acquiring HSD3B1(1245C) may be underestimated because intratumoural heterogeneity may decrease the detection of this mutation. In fact, sustained intratumoural DHT synthesis by $3 \beta \mathrm{HSD} 1(367 \mathrm{~T})$ may have an autocrine as well as a paracrine function. Autocrine function would permit a tumour cell to supply its own DHT for growth. In the paracrine scenario, a few tumour cells acquiring the
HSD3B1(1245C) mutation may supply DHT to surrounding tumour cells that lack the mutation. The paracrine model is evidenced by detection of $\left[{ }^{3} \mathrm{H}\right]$-labelled DHT in the culture medium (Chang et al, 2013). The small proportion of cells required to achieve a paracrine effect may hinder detection of this mutation, when present.

Notably, over 100 germline single-nucleotide polymorphisms associated with steroidogenic enzymes have been identified. Although the functional consequences of many of these are yet to be characterised, some single-nucleotide polymorphisms associated with steroidogenic enzymes, including aromatase, have been associated with more rapid development of CRPC (Ross et al, 2008).

Sustained androgen metabolism for treatment resistance. The clinical benefit of the CYP17A1 inhibitor abiraterone acetate demonstrates the concept that androgen metabolism is a central driver of CRPC progression (de Bono et al, 2011; Ryan et al, 2013). Residual androgen metabolites remain detectable in abiraterone acetate-treated patients (Attard et al, 2012), suggesting that pharmacologic inhibition of CYP17A1 by abiraterone acetate in patients is incomplete. Of note, the HSD3B1(1245C) mutation also occurs in a mouse xenograft model of abiraterone acetate resistance (Chang et al, 2013), signifying that in addition to driving resistance to $\mathrm{ADT}$, this mutation also enables resistance to abiraterone acetate by utilising residual androgens in the context of incomplete CYP17A1 inhibition. However, the role of HSD3B1(1245C) in clinical resistance to abiraterone acetate has yet to be determined. Despite the potent AR antagonist activity of enzalutamide, DHT, which has an even higher AR-binding affinity, would outcompete enzalutamide for the ligand-binding domain at sufficient concentrations (Tran et al, 2009). Conceivably, HSD3B1(1245C) might also enable enzalutamide resistance by this mechanism. However, this possibility remains to be explored.

Although abiraterone acetate and enzalutamide provide a survival benefit (de Bono et al, 2011; Scher et al, 2012), resistance to such therapies almost always develops, and CRPC remains incurable. Therefore, finding novel druggable targets for treating CRPC is essential. In clinical oncology, cancer therapies are evolving from administration of cytotoxic chemotherapy with treatment selection generally not based on patient tumour biology, to personalised cancer therapy, where molecularly tailored treatment is matched to a genetic defect that drives disease progression and is identified in the tumour of the individual patient. Examples of personalised cancer therapy include the use of EGF receptor inhibitors to target EGF receptor mutations in nonsmall-cell lung cancer (Lynch et al, 2004; Kobayashi et al, 2005) and BRAF inhibitors for BRAF mutation-driven melanoma (Chapman et al, 2011). No similar use of individualised patient tumour genetics to identify a matching pharmacologic treatment is available in the standard of care for CRPC. The identification of a gain-of-function mutation in HSD3B1 may validate a new target for individualised cancer therapy in CPRC.

\section{TOWARD A CURATIVE PARADIGM FOR RECURRENT} LOCALISED DISEASE

Targeting androgen metabolism in the preoperative period. Prostatectomy is potentially curative for patients with localised prostate cancer. Targeting the androgen pathway in the preoperative period may provide an opportunity to improve oncologic outcomes for patients who present with high-risk disease and therefore have a higher likelihood of recurrence. In other words, the right neoadjuvant treatment could prevent death in a patient who is otherwise destined to recur after localised therapy. Studies of treated tumours may shed light on the tumour metabolism 
parameters and therefore provide insight on whether a patient is likely to respond to currently available or emerging drug therapies. Efstathiou et al (2012) evaluated the effects of abiraterone acetate plus medical castration (GnRH agonist) vs castration alone in localised high-risk prostate cancer followed by prostatectomy in a phase 2 preoperative study. Patients with high-risk disease were defined as having $\geqslant \mathrm{cT} 1$ disease and a biopsy Gleason score of $\geqslant 8$, or $\geqslant \mathrm{T} 2 \mathrm{~b}$ plus Gleason $\geqslant 7$ and PSA $\geqslant 10 \mathrm{ng} \mathrm{ml}^{-1}$. Patients were randomised $2: 1$ to a 12 -week course of abiraterone acetate plus prednisone plus castration or castration alone. The primary endpoint was the decrease in stage $(\leqslant y p T 2)$ and safety. The secondary aims included assessing differences in androgen biosynthesis, androgen signalling, proliferation, apoptosis, and candidate resistance pathways. When compared with castration alone, the preoperative treatment of abiraterone acetate plus prednisone plus castration resulted in greater cytoreduction and greater suppression of PSA and androgen signalling. Nearcomplete cytoreduction (scattered cells $<6 \mathrm{~mm}$ ) was observed in $24 \%$ of the patients receiving abiraterone acetate plus prednisone plus castration $v s 8 \%$ of those who received castration alone.

Taplin et al (2012) conducted a phase 2 trial of preoperative abiraterone acetate and castration for patients diagnosed with localised high-risk $(\geqslant 3$ positive biopsies, Gleason score $\geqslant 7$ $(4+3)$, T3, PSA $\geqslant 20 \mathrm{ng} \mathrm{ml}^{-1}$, or PSA velocity $>2 \mathrm{ng} \mathrm{ml}^{-1}$ per year) prostate cancer. A main focus of the study was to measure intraprostatic T and DHT; one of several secondary endpoints was pathologic complete response or near-complete response in the prostatectomy specimen. Patients were randomised to receive abiraterone acetate plus prednisone and castration or castration alone for 12 weeks. At 12 weeks, a prostate biopsy was done to measure tissue androgen levels. All men subsequently received an additional 12 weeks of abiraterone acetate plus prednisone and castration followed by radical prostatectomy. PSA decrease to $<0.2 \mathrm{ng} \mathrm{ml}^{-1}$ occurred earlier in the abiraterone acetate plus prednisone with castration group compared with the castration alone group. Pathologic complete response and near-pathologic complete response were more pronounced in patients receiving the longer treatment course of abiraterone acetate $(34 \%)$ than those who only received 12 weeks (15\%). These findings are promising and need to be further validated with a larger trial and long-term follow-up to fully appreciate the role of targeted therapy in the preoperative period for high-risk patients. Both of these studies noted that abiraterone acetate was well tolerated with no new safety concerns.

\section{Investigation of adrenal androgen metabolism in localised prostate cancer tissue}

Model for the study of metabolism in benign and malignant prostate tissue. Preoperative studies have suggested that pathologic responses may be increased with the addition of abiraterone acetate to castration treatment. To gain a better understanding of the underlying mechanisms of response and resistance in the tumour, more studies of localised prostatic tissues are required. The use of human cell lines, xenografts, and animal models have led to great advances in our understanding of prostate cancer biology (Pienta et al, 2008). However, these methods and models have their limitations, as human cell lines are typically derived from metastatic tumours and do not generally represent the biology of localised tumours. This is illustrated by the examples that some cell lines have loss of AR expression, loss of PSA expression, or mutations in $\mathrm{AR}$, none of which is representative of localised prostate cancer (Sobel and Sadar, 2005a,b). A third type of analysis, which has been more challenging to incorporate into prostate cancer research but may be essential to develop, is ex vivo analysis of prostate cancer tissue. The power of an ex vivo analysis lies in its preservation of the native tissue's architecture and thus the major components of its microenvironment, which retain the crosstalk that occurs between epithelial and stromal cells. Therefore, ex vivo analysis allows investigators to determine metabolic pathway activity within the native tissue microenvironment, which is not usually possible in a human context with cell lines or xenograft models.

In early work, we have found that treating fresh prostatectomy specimens ex vivo with $\left[{ }^{3} \mathrm{H}\right]$-labelled DHEA, followed by analysis of steroid metabolites, reproducibly demonstrates metabolic flux to downstream products (Ercole et al, 2014). Although some challenges exist with the specimens procured that reflect the inherent heterogeneity of the prostate tissues and tumours, we have had consistent initial results. The majority of tissue we have obtained is benign, as patients undergoing prostatectomy with curative intent tend to have low-volume, localised disease. We anticipate obtaining additional specimens to validate our findings and better assess differences in the heterogeneity of androgen metabolism, both across patients and between benign and malignant tissues.

Applications for ex vivo analysis. The advantage of ex vivo analysis is that it provides a platform to better understand the mechanisms that underlie tumour heterogeneity in the androgen metabolic pathway and identify other therapeutic targets that might regulate responses to pharmacologic therapy within the context of the native prostate architecture. Our ex vivo protocol may be used to assess drug targets and determine tissue response to hormonal therapies by targeting the various pathway components. Tissue from a patient with localised prostate cancer could be analysed to determine whether the tumour's metabolic parameters show characteristics of more aggressive or resistant disease. Similarly, targeted genetic characterisation immediately upon biopsy may help to determine whether patients with localised disease have genetic alterations present that mandate an alternative treatment paradigm, as these men may have a higher risk of disease recurrence and faster progression to advanced disease. For example, knowledge of the HSD3B1 genotype in a patient might provide insight into that patient's likelihood of response to hormonal therapy.

The ex vivo analysis of whole tissue takes into account how the dynamic microenvironment regulates androgen metabolism. Tissues collected sustained metabolic activity well into $72 \mathrm{~h}$ of incubation. Ex vivo analysis also provides an opportunity to validate and evaluate other anticancer agents. Centenera et al (2012) used ex vivo cultures to assess the biologically active dose of an Hsp90 inhibitor. In their protocol, an 8-mm core of prostatectomy tissue was dissected into $1-\mathrm{mm}^{3}$ pieces and cultured on a presoaked gelatin sponge. When they compared their cell line and animal model results to the ex vivo results, a difference was appreciated, with the ex vivo analysis showing antiproliferative and proapoptotic activity with the Hsp90 inhibitor that was not observed with the other techniques.

\section{CONCLUSION}

A major driving force behind the progression from localised prostate cancer to advanced disease to CRPC is mediated by androgens and alterations in the androgen pathway that sustain the disease. Therefore, it is imperative to focus future investigations on understanding the intricacies that dictate androgen metabolism and thereby regulate AR activation. As we move forward, we need to build on knowledge arising from studies of cell lines and animal models and further validate those findings with ex vivo analysis of patient tissues. Ultimately, finding answers to treatment resistance will of necessity require investigation of clinical tumours. 


\section{ACKNOWLEDGEMENTS}

This publication has been funded in part by a Howard Hughes Medical Institute Physician-Scientist Early Career Award, the Prostate Cancer Foundation, an American Cancer Society Research Scholar Award (12-038-01-CCE), grant PC080193 from the U.S. Army Medical Research and Materiel Command, 1R01CA168899 and 1R01CA172382-01 from the National Institutes of Health, to NS.

\section{REFERENCES}

Adeniji AO, Chen M, Penning TM (2013) AKR1C3 as a target in castrate resistant prostate cancer. J Steroid Biochem Mol Biol 137: 136-149.

Attard G, de Bono JS (2011) Translating scientific advancement into clinical benefit for castration-resistant prostate cancer patients. Clin Cancer Res 17: $3867-3875$.

Attard G, Reid AH, Auchus RJ, Hughes BA, Cassidy AM, Thompson E, Oommen NB, Folkerd E, Dowsett M, ArlT W, de Bono JS (2012) Clinical and biochemical consequences of CYP17A1 inhibition with abiraterone given with and without exogenous glucocorticoids in castrate men with advanced prostate cancer. J Clin Endocrinol Metab 97: 507-516.

Centenera MM, Gillis JL, Hanson AR, Jindal S, Taylor RA, Risbridger GP, Sutherland PD, Scher HI, Raj GV, Knudsen KE, Yeadon T, Tilley WD, Butler LM (2012) Evidence for efficacy of new Hsp90 inhibitors revealed by ex vivo culture of human prostate tumors. Clin Cancer Res 18: $3562-3570$.

Chang KH, Li R, Kuri B, Lotan Y, Roehrborn CG, Liu J, Vessella R, Nelson PS, Kapur P, Guo X, Mirzaei H, Auchus RJ, Sharifi N (2013) A gain-offunction mutation in DHT synthesis in castration-resistant prostate cancer. Cell 154: 1074-1084.

Chang KH, Li R, Papari-Zareei M, WatumulL L, Zhao YD, Auchus RJ, Sharifi N (2011) Dihydrotestosterone synthesis bypasses testosterone to drive castration-resistant prostate cancer. Proc Natl Acad Sci USA 108: 13728-13733.

Chapman PB, Hauschild A, Robert C, Haanen JB, Ascierto P, Larkin J, Dummer R, Garbe C, Testori A, Maio M, Hogg D, Lorigan P, Lebbe C, Jouary T, Schadendorf D, Ribas A, O’Day SJ, Sosman JA, Kirkwood JM, Eggermont AM, Dreno B, Nolop K, Li J, Nelson B, Hou J, Lee RJ, Flaherty KT, Mcarthur GA (2011) Improved survival with vemurafenib in melanoma with BRAF V600E mutation. $N$ Engl J Med 364: 2507-2516.

de Bono JS, Logothetis CJ, Molina A, Fizazi K, North S, Chu L, Chi KN, Jones RJ, Goodman Jr OB, Saad F, Staffurth JN, Mainwaring P, Harland S, Flaig TW, Hutson TE, Cheng T, Patterson H, Hainsworth JD, Ryan CJ, Sternberg CN, Ellard SL, Flechon A, Saleh M, Scholz M, Efstathiou E, Zivi A, Bianchini D, Loriot Y, Chieffo N, Kheoh T, Haqq CM, Scher HI (2011) Abiraterone and increased survival in metastatic prostate cancer. N Engl J Med 364: 1995-2005.

Efstathiou E, Davis JW, Troncoso P, Titus MA, Hoang A, Wen S, Zurita AJ, Tran N, Molina A, Logothetis C (2012) Cytoreduction and androgen signaling modulation by abiraterone acetate (AA) plus leuprolide acetate (LHRHa) versus LHRHa in localized high-risk prostate cancer (PCa): Preliminary results of a randomized preoperative study. J Clin Oncol 30(suppl (May 20 Supplement)): 4556.

Ercole CE, Chang K-H, Aboali G, Magi-Galluzzi C, Stephenson AJ, Klein EA, Sharifi N (2014) Dehydroepiandrosterone metabolism in fresh human prostate: A feasibility study. J Clin Oncol 32(suppl 4): abstr 225 .

Geller J, Albert J, De La Vega D, Loza D, Stoeltzing W (1978) Dihydrotestosterone concentration in prostate cancer tissue as a predictor of tumor differentiation and hormonal dependency. Cancer Res 38: 4349-4352.

Kobayashi S, Boggon TJ, Dayaram T, Janne PA, Kocher O, Meyerson M, Johnson BE, Eck MJ, Tenen DG, Halmos B (2005) EGFR mutation and resistance of non-small-cell lung cancer to gefitinib. N Engl J Med 352: 786-792.

Labrie F (2011) Blockade of testicular and adrenal androgens in prostate cancer treatment. Nat Rev Urol 8: 73-85.
Li J, Yen C, Liaw D, Podsypanina K, Bose S, Wang SI, Puc J, Miliaresis C, Rodgers L, Mccombie R, Bigner SH, Giovanella BC, Ittmann M, Tycko B, Hibshoosh H, Wigler MH, Parsons R (1997) PTEN, a putative protein tyrosine phosphatase gene mutated in human brain, breast, and prostate cancer. Science 275: 1943-1947.

Lynch TJ, Bell DW, Sordella R, Gurubhagavatula S, Okimoto RA, Brannigan BW, Harris PL, Haserlat SM, Supko JG, Haluska FG, Louis DN, Christiani DC, Settleman J, Haber DA (2004) Activating mutations in the epidermal growth factor receptor underlying responsiveness of non-small-cell lung cancer to gefitinib. N Engl J Med 350: 2129-2139.

Montgomery RB, Mostaghel EA, Vessella R, Hess DL, Kalhorn TF, Higano CS, True LD, Nelson PS (2008) Maintenance of intratumoral androgens in metastatic prostate cancer: a mechanism for castration-resistant tumor growth. Cancer Res 68: 4447-4454.

Pienta KJ, Abate-Shen C, Agus DB, Attar RM, Chung LW, Greenberg NM, Hahn WC, Isaacs JT, Navone NM, Peehl DM, Simons JW, Solit DB, Soule HR, Vandyke TA, Weber MJ, Wu L, Vessella RL (2008) The current state of preclinical prostate cancer animal models. Prostate 68 : 629-639.

Ross RW, Oh WK, Xie W, Pomerantz M, Nakabayashi M, Sartor O, Taplin ME, Regan MM, Kantoff PW, Freedman M (2008) Inherited variation in the androgen pathway is associated with the efficacy of androgen-deprivation therapy in men with prostate cancer. J Clin Oncol 26: 842-847.

Russell DW, Wilson JD (1994) Steroid 5 alpha-reductase: two genes/two enzymes. Annu Rev Biochem 63: 25-61.

Ryan CJ, Smith MR, de Bono JS, Molina A, Logothetis CJ, de Souza P, Fizazi K, Mainwaring P, Piulats JM, Ng S, Carles J, Mulders PF, Basch E, Small EJ, Saad F, Schrijvers D, Van Poppel H, Mukherjee SD, Suttmann H, Gerritsen WR, Flaig TW, George DJ, Yu EY, Efstathiou E, Pantuck A, Winquist E, Higano CS, Taplin ME, Park Y, Kheoh T, Griffin T, Scher HI, Rathkopf DE (2013) Abiraterone in metastatic prostate cancer without previous chemotherapy. $N$ Engl J Med 368: 138-148.

Scher HI, Fizazi K, Saad F, Taplin ME, Sternberg CN, Miller K, De Wit R, Mulders P, Chi KN, Shore ND, Armstrong AJ, Flaig TW, Flechon A, Mainwaring P, Fleming M, Hainsworth JD, Hirmand M, Selby B, Seely L, de Bono JS (2012) Increased survival with enzalutamide in prostate cancer after chemotherapy. N Engl J Med 367: 1187-1197.

Scher HI, Sawyers CL (2005) Biology of progressive, castration-resistant prostate cancer: directed therapies targeting the androgen-receptor signaling axis. J Clin Oncol 23: 8253-8261.

Sharifi N (2013a) Mechanisms of androgen receptor activation in castration-resistant prostate cancer. Endocrinology 154: 4010-4017.

Sharifi N (2013b) Minireview: androgen metabolism in castration-resistant prostate cancer. Mol Endocrinol 27: 708-714.

Sharifi N, Gulley JL, Dahut WL (2005) Androgen deprivation therapy for prostate cancer. JAMA 294: 238-244.

Siegel R, Naishadham D, Jemal A (2013) Cancer statistics, 2013. CA Cancer J Clin 63: 11-30.

Simard J, Ricketts ML, Gingras S, Soucy P, Feltus FA, Melner MH (2005) Molecular biology of the 3beta-hydroxysteroid dehydrogenase/delta5delta4 isomerase gene family. Endocr Rev 26: 525-582.

Sobel RE, Sadar MD (2005a) Cell lines used in prostate cancer research: a compendium of old and new lines-part 1. J Urol 173: 342-359.

Sobel RE, Sadar MD (2005b) Cell lines used in prostate cancer research: a compendium of old and new lines-part 2. J Urol 173: 360-372.

Stanbrough M, Bubley GJ, Ross K, Golub TR, Rubin MA, Penning TM, Febbo PG, Balk SP (2006) Increased expression of genes converting adrenal androgens to testosterone in androgen-independent prostate cancer. Cancer Res 66: 2815-2825.

Taplin M-E, Montgomery RB, Logothetis C, Bubley GJ, Richie JP, Dalkin BL (2012) Effect of neoadjuvant abiraterone acetate (AA) plues leuprolide acetate (LHRHa) on PSA, pathologic complete response (pCR), and near pCR in localized high-risk prostate cancer (LHRPC): Results of a randomized phase II study. J Clin Oncol 30(suppl (May 20 Supplement): $452130,4521$.

Thigpen AE, Cala KM, Russell DW (1993) Characterization of Chinese hamster ovary cell lines expressing human steroid 5 alpha-reductase isozymes. J Biol Chem 268: 17404-17412.

Titus MA, Schell MJ, Lih FB, Tomer KB, Mohler JL (2005) Testosterone and dihydrotestosterone tissue levels in recurrent prostate cancer. Clin Cancer Res 11: 4653-4657. 
Tomlins SA, Laxman B, Dhanasekaran SM, Helgeson BE, Cao X, Morris DS, Menon A, Jing X, Cao Q, Han B, Yu J, Wang L, Montie JE, Rubin MA, Pienta KJ, Roulston D, Shah RB, Varambally S, Mehra R, Chinnaiyan AM (2007) Distinct classes of chromosomal rearrangements create oncogenic ETS gene fusions in prostate cancer. Nature 448: 595-599.

Tran C, Ouk S, Clegg NJ, Chen Y, Watson PA, Arora V, Wongvipat J, Smith-Jones PM, Yoo D, Kwon A, Wasielewska T, Welsbie D, Chen CD, Higano CS, Beer TM, Hung DT, Scher HI, Jung ME, Sawyers CL (2009)
Development of a second-generation antiandrogen for treatment of advanced prostate cancer. Science 324: 787-790.

(c) (1) (2) (2) This work is licensed under the Creative Commons cc. At No SA Atribution-NonCommercial-Share Alike 3.0 Unported License. To view a copy of this license, visit http://creativecommons. org/licenses/by-nc-sa/3.0/ 